\title{
A periurbanização de Lutzomyia whitmani em área de foco de leishmaniose cutânea, no Estado do Maranhão, Brasil
}

\author{
Lutzomyia whitmani periurbanization in a focus of cutaneous \\ leishmaniasis in the State of Maranhão, Brazil
}

Francisco Santos Leonardo ${ }^{1}$ e José Manuel Macário Rebêlo ${ }^{2}$

\begin{abstract}
RESUM0
Em um inquérito entomológico realizado em 2000, na zona periurbana do município de Dom Pedro-MA, pretendia-se estimar a abundância de Lutzomyia longipalpis, por conta da ocorrência de um óbito suspeito de calazar. Entretanto, constatou-se que do total de 2.961 flebótomos capturados no peridomicílio, 82,4\% ( 2.440 espécimes) eram de Lutzomyia whitmani. Esta associação vem determinando um novo padrão de transmissão da leishmaniose cutânea ( 0 urbano), como vem acontecendo com o calazar nordestino.
\end{abstract}

Palavras-chaves: Lutzomyia whitmani. Leishmaniose cutânea. Estado do Maranhão.

\begin{abstract}
An entomological survey was performed in the periurban area of the municipality of Dom Pedro in the state of Maranhão in 2000, in order to estimate the abundance of Lutzomyia longipalpis, due to the occurrence of one suspect death caused by kala azar. However, it was surprisingly verified that $82.4 \%$ (2,440 specimens) from the total of 2,961 sand flies captured in the peridomicile were Lutzomyia whitmani. This association has indicated a new pattern for cutaneous leishmaniasis transmission ( urban), as has been observed with regard to kala azar in the northeast of Brazil.
\end{abstract}

Key-words: Lutzomyia whitmani. Cutaneous leishmaniasis. State of Maranhão.

A Lutzomyia (Nyssomyia) whitmani Antunes \& Coutinho, 1939 é uma espécie (sensu lato) de ampla distribuição na América do Sul ${ }^{20}$. No Brasil, desenvolveu hábito antropofilico e ocorre nos domicílios humanos e abrigos animais de algumas áreas do Nordeste ${ }^{13}{ }^{19}$ e Sudeste $^{89}$. No Centro-Oeste, a antropofilia tem sido notada, mas esta prática ainda é exofílica ${ }^{6}$, enquanto no Sul tem sido associada com ambientes silvestres ${ }^{18}$.

Ao contrário do que se observa nas áreas onde transmite a Leishmania (V.) braziliensis, na Região Norte ainda conserva 0 hábito silvestre e é incriminada na transmissão de Leishmania (V.) shawi?

Na Amazônia do Maranhão, é abundante no ambiente silvestre e peridoméstico da zona rural ${ }^{1415}$, enquanto no leste do Estado a freqüência dos espécimes nas residências rurais ainda é muito baixa ${ }^{13}$.

Neste trabalho, estudou-se a freqüência de espécimes de L whitmani na zona periurbana do município de Dom Pedro, área de ocorrência de leishmaniose cutânea (LC).

0 município, situado a $5^{\circ} 9^{\prime} \mathrm{Se}$ e $44^{\circ} 28^{\prime} \mathrm{W}$, na região centroleste do Maranhão, compreende uma área de $756,6 \mathrm{~km}^{2}$ e uma população total de 21.779 habitantes ( 10.559 homens e 11.220 mulheres), sendo 13.867 urbanos e 7.912 rurais. A quantidade de domicílios é de 6.046, dentre estes, 5.191 encontram-se ocupados. 0 clima é o quente e úmido em transição para o quente semi-árido, com índice pluviométrico anual de $1.200 \mathrm{~mm}$ ( Figura 1). A vegetação original, também de transição, denominada floresta estacional perenifólia

\footnotetext{
1. Distrito Sanitário de Codó da Fundação Nacional de Saúde. São Luís, MA. 2. Laboratório de Entomologia e Vetores do Departamento de Patologia da Universidade Federal do Maranhão, São Luís, MA.

Endereço para correspondência: Dr. José Manuel Macário Rebêlo. Praça Madre Deus 2, 65025-560 São Luís, MA, Brasil.

Telefax: 5598 248-2929

e-mail: macariorebelo@uol.com.br

Recebido para publicação em 6/2/2003

Aceito em 19/2/2003
} 


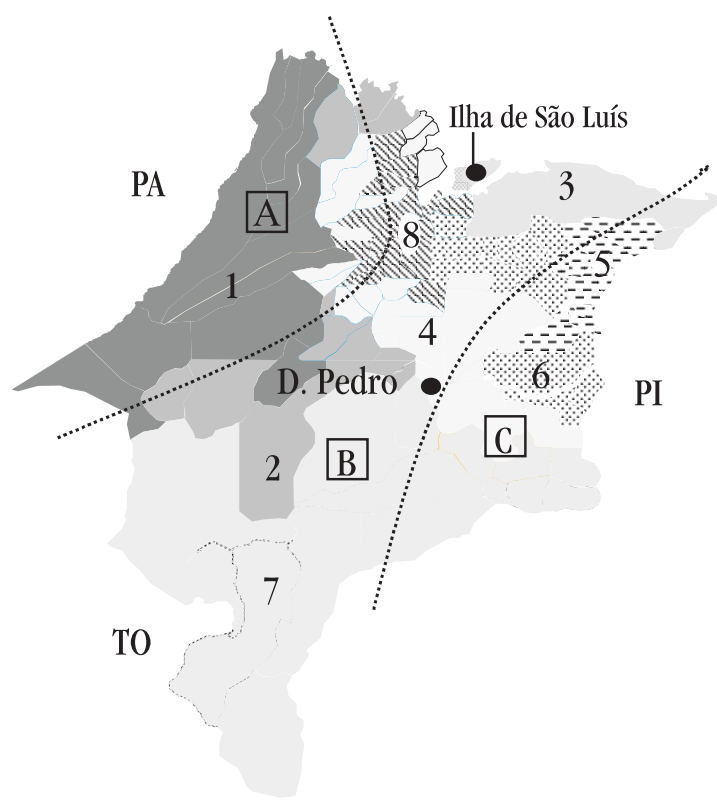

Vegetação

1 - floresta estacional perenifólia densa

2 - floresta estacional perenifólia aberta

3 - dunas, restinga, mangue e cerrado

4 - floresta estacional perenifólia aberta com babaçu

5 - cerrado e caatingas

6 - floresta estacional perenifólia aberta com babaçu e manchas de cerrado

7 - cerrados meridionais

8 - campo aluvial flúvio marinho

(.......) Divisão de zonas climáticas

A. clima quente e úmido

B. clima quente semi-úmido

C. clima semi-árido

Figura 1 - Mapa do Estado do Maranhão mostrando as fitorregiões e a localização do município de Dom Pedro, onde registrou-se a presença de Lutzomyia whitmani no ambiente periurbano.

aberta com babaçu ou floresta latifoliada semidecídua, estende-se entre 0 cerrado e a floresta perene latifoliada densa e entre esta e a caatinga. É difícil caracteriza-la, tanto do ponto de vista estrutural, como do ponto de vista florístico, tais as nuanças que apresenta.

0 estudo havia sido planejado para estimar a densidade de L longipalpis, por conta da ocorrência de um óbito suspeito de calazar. Então, realizou-se um inquérito entomológico no período de 26 a 30 de junho de 2000, durante cinco noites consecutivas (das 18 às 6 horas) em uma residência de três bairros periurbanos contíguos ao centro da cidade por meio de outros bairros. Duas residências tinham o quintal arborizado, contíguo à capoeira adjacente, e na terceira, fazia contato com uma área descampada. Em cada residência foram instaladas duas armadilhas CDC a uma altura de 1,5 metros, sendo uma no galinheiro presente no quintal (peridomicílio), e outra no dormitório (intradomicílio). A distância dos galinheiros para as residências variaram de 5 a 10 metros. Considerando 6 armadilhas $\mathrm{x} 12$ horas $\mathrm{x} 5$ noites, 0 esforço de captura foi de 360 horas.

Do total de 2.961 espécimes de flebótomos capturados, apenas 17,6\% eram de L longipalpis contra 82,4\% (2.440 exemplares) de L. whitmani. Destes, 98,7\% (2.408 espécimes) estavam no peridomicílio, contra 1,3\% (32 espécimes) dentro das habitações. Estes são dados que à primeira vista impressionam, sobretudo em se tratando de uma área tida como endêmica de calazar. Todavia, somente naquele ano haviam sido notificados aproximadamente 42 casos de LC em todo o município, e no ano seguinte (2001), as notificações aumentaram para 58 casos, atingindo 0 sexo masculino ( 34 casos) e o feminino ( 24 casos) (Gerência de Qualidade de Vida do Estado do Maranhão, 2002). A doença predominou no sexo masculino (58,6\%), mas a freqüência no feminino foi elevada $(41,4 \%)$, sugerindo transmissão peridomiciliar.
Pelo que se pode apurar, em conversa com membros da população local, o crescimento da cidade, nos últimos anos, foi acompanhado por um intenso desmatamento da cobertura vegetal periférica, predominando, atualmente, a capoeira e babaçu nas proximidades da cidade. Esse processo, provavelmente, criou condições favoráveis para a proliferação do vetor. A julgar pela freqüência de flebotomíneos capturados nos galinheiros, a criação de animais domésticos parece que também tem contribuído para atrair 0 vetor para a zona periurbana e aumentar a participação daqueles no ciclo epidemiológico da LC, fenômeno conhecido em áreas endêmicas da infecçã $0^{416}$.

A ampla distribuição de Lutzomyia whitmani e a associação com Leishmania, em distintas regiões geográficas ${ }^{1}{ }^{7}$, tem suscitado a hipótese dela constituir um complexo de espécies crípticas alopátricas, com tipos característicos de comportamento epidemiológic ${ }^{10}$. Estudos de mt-DNA indicaram a presença de pelo menos três linhagens filogenéticas ${ }^{11}$, as quais teriam divergido desde 0 final do Pliocen $0^{5}$ e, agora habitam três zonas bioclimáticas: a Floresta Amazônica; a zona dos Cerrados e a Mata Attântica ${ }^{11}$.

A população de L whitmani de D. Pedro ainda não é conhecida neste aspecto, entretanto, aquela encontrada no ambiente peridoméstico na Amazônia do Maranhão $0^{14}{ }^{15}$, pertence à linhagem amazônica, enquanto sua peridomesticidade pode ter resultado da seleção de um comportamento prévio, pouco freqüente, ou do fluxo de genes da linhagem extra-amazônica ${ }^{12}$. Esta última hipótese é sustentada pelo extensivo processo de desmatamento ocorrido em Buriticupu, desde 0 início da década de 1970, transformando a região em um gradiente ecológico ( ecótono) entre a floresta amazônica e os cerrados. Esse processo aumentou o contato do vetor com as pessoas e o risco de adquirirem a infecção na própria habitação ou em sua cercania. 
Os registros da Gerência de Qualidade de Vida do Estado do Maranhão indicam que na década de 90 , houve expansão da doença para novas fronteiras, inclusive para a região de D. Pedro. Tal fenômeno ocorreu, provavelmente, devido ao desmatamento nas áreas situadas entre as grandes cidades, em função de implantação dos diversos projetos de desenvolvimento. De acordo com os registros da FUNASA (Regional do Maranhão), a incidência da doença em D. Pedro, evoluiu de 34,61/100 mil habitantes no ano de 1994 para 74,23, em 1999. A existência da doença pode estar relacionada com a presença de $\mathrm{L}$ whitmani. 0 achado deste estudo é um alerta de que L whtimani vem se adaptando à zona periurbana podendo determinar um novo padrão de transmissão da LC no Maranhão - 0 urbano.

\section{REFERÊNCIAS BIBLIOGRÁFICAS}

1. Azevedo ACR, Rangel EF, Costa ME, David J, Vasconcelos AW, Lopes UG. Natural infection of Lutzomyia (Nyssomyia) whitmani (Antunes \& Coutinho, 1939) by Leishmania of the braziliensis complex in Baturité, Ceará State, Northeast Brazil. Memórias do Instituto Oswaldo Cruz 85: 251, 1990.

2. Barreto AC, Cuba-Cuba C, Vexenat JA, Rosa AC, Marsden PD, Magalhães AV. Características epidemiológicas da leishmaniose tegumentar americana em uma região endêmica do Estado da Bahia. II. Leishmaniose canina. Revista da Sociedade Brasileira de Medicina Tropical 17: 59-65, 1984.

3. Brandão-Filho SP, Carvalho FG, Brito MEF, Almeida FA, Nascimento LA. American cutaneous leishmaniasis in Pernambuco, Brazil: Ecoepidemiological aspects in "Zona da Mata" region. Memórias do Instituto Oswaldo Cruz 89: 445-449, 1994.

4. Dias M, Mayrink W, Deane LM, COSTA CA, Magalhães PA, Melo MN, Batista SM, Araújo FG, Coelho MV, Williams P. Epidemiologia da leishmaniose tegumentar americana. I. Estudo de reservatórios em áreas endêmica no Estado de Minas Gerais. Revista do Instituto de Medicina Tropical de São Paulo 19:403-10, 1977.

5. Esseghir S, Ready PD, Killick-Kendrick R, Bem-Ismail R. Mithocondrial haplotypes and phylogeography of Phlebotomus vectors of Leishmania major. Insect Molecular Biology 6:211-225, 1997.

6. Galati $\mathrm{EAB}$, Nunes VLB, Dorval MEC, Oshiro ET, Cristaldo G, Espíndola MA, Rocha HC, Garcia WB. Estudo dos flebotomíneos (Diptera, Psychodidae) em área de leishmaniose tegumentar, no Estado de Mato Grosso do Sul, Brasil. Revista de Saúde Pública 30: 115-128, 1996.

7. Lainson R, Shaw JJ, Silveira FT, Souza AAA, Braga RR, Ishikawa EAY., 1994. The dermal leishmaniases of Brazil, with special reference to the ecoepidemiology of the disease in Amazonia. Memórias Instituto Oswaldo Cruz, 89:435-443, 1994
8. Mayo RC, Casanova C, Mascarini LM, Pignatti MG, Rangel O, Galati EAB, Wanderley DMV, Corrêa FMA. Flebotomíneos (Diptera, Psychodidae) de área de transmissão de leishmaniose tegumentar americana, no município de Itupeva, região Sudeste do Estado de São Paulo, Brasil. Revista da Sociedade Brasileira de Medicina Tropical 31:339-345, 1998.

9. Passos VMA, Falcão AL, Marzochi MCA, Gontijo CMF, Dias ES, BarbosaSantos EGO, Guerra HL, Katz N. Epidemiological aspects of american cutaneous leishmaniasis in a periurban area of the metropolitan region of Belo Horizonte, Minas Gerais, Brazil. Memórias do Instituto Oswaldo Cruz 88: 103-110, 1993.

10. Rangel EF, Lainson R, Souza AA, Ready P, Azevedo ACR. Variation between geographical populations of Lutzomyia (Nyssomyia) whitmani (Antunes \& Coutinho, 1939) sensu lato (Diptera: Psychodidae: Phlebotominae) in Brazil. Memórias Instituto Oswaldo Cruz, 91:43-50, 1996.

11. Ready PD, Day JC, Souza AA, Rangel EF, Davies CR. Bulletin of Entomological Research 87:187-195, 1997.

12. Ready PD, Souza AA, Rebêlo JMM, Day JC, Silveira F, Campbell-Lendrum D, Davies CR, Costa JML. Phylogenetic species and domesticity of Lutzomyia whitmani at the south-east boundary of Amazonian Brazil. Transaction of the Royal Research Society of Tropical Medicine and Hygiene 92: 159160, 1998.

13. Rebêlo JMM, Leonardo FS, Costa JML, Pereira YNO, Silva FS. Flebotomíneos (Diptera, Psychodidae) de área endêmica de leishmaniose na região dos cerrados, Estado do Maranhão, Brasil. Cadernos de Saúde Pública 15: 623-630, 1999

14. Rebêlo JMM, Oliveira ST, Barros VL, Silva FS. Flebotomíneos (Diptera, Psychodidae) de Lagoas, município de Buriticupu, Amazônia maranhense. I - Riqueza e abundância relativa das espécies em área de colonização recente. Revista da Sociedade Brasileira de Medicina Tropical 33: 11-19, 2000a.

15. Rebêlo JMM, Oliveira ST, Barros VLL, Silva FS. Flebotomíneos da Amazônia maranhense. IV - Riqueza e abundância relativa das espécies em área de colonização antiga. Entomologia y Vectores 7: 61-72, 2000b.

16. Service MW. Agricultural development and arthropod-borne diseases: a review. Revista de Saúde Pública 25:165-78, 1991.

17. Silva AR, Martins G, Melo JEM, Araújo JP, Mendes MG. Surto epidêmico de leishmaniose tegumentar americana na colonização agrícola de Buriticupu (MA). Revista do Instituto de Medicina Tropical de São Paulo. 21: 45-50. 1979.

18. Teodoro U, Kühl JB, Rodrigues M, Santos ES, Santos DR, Maróstica MF Flebotomíneos coletados em matas remanescentes e abrigos de animais silvestres de zoológico no perímetro urbano de Maringá, Sul do Brasil. Estudo preliminar. Revista da Sociedade Brasileira de Medicina Tropical 31:517-522, 1998

19. Vexenat JA, Barretto AC, Cuba CC, Marsden PD. Características epidemiológicas da leishmaniose tegumentar americana em uma região endêmica do estado da Bahia. III. Fauna flebotomínica. Memórias do Instituto Oswaldo Cruz 81:293-301, 1986

20. Young DG, Duncan MA. Guide to the identification and geographic distribution of Lutzomyia sandflies in Mexico, the West Indies, Central and South America (Diptera: Psychodidae). Memories American Entomology Institute 54:1-881, 1994 